\title{
Public R\&D Centers, Social Agents of the Socio Economic Innovation System of Mexico
}

\author{
Vega-González \\ Universidad Nacional Autónoma de México, Centro de Ciencias Aplicadas y Desarrollo \\ Tecnológico, Circuito Exterior S/N, Ciudad Universitaria, México \\ Tel: 52-556-228-626Ｅ-mail: lrvg@ servidor.unam.mx \\ Luís Roberto \\ Universidad Nacional Autónoma de México, Centro de Ciencias Aplicadas y Desarrollo \\ Tecnológico, Circuito Exterior S/N, Ciudad Universitaria, México \\ E-mail: roberto.vega@ccadet.unam.mx
}

Received: December 19, 2014 Accepted: January 4, 2015

doi:10.5296/ber.v5i1.6805 URL: http://dx.doi.org/10.5296/ber.v5i1.6805

\begin{abstract}
Since late 1990's in the first world was proposed a new mission for the public universities beyond the teaching and research and development (R\&D); their conversion as agents for economic development through the knowledge transferred to other society organizations. More than twenty years have passed and now we can see that in practice achieving this has been very difficult for public universities of developing countries. In the case of the Mexican Centre presented, it is shown that public University have historically established strong links with other public governmental organizations and that the technology and the knowledge products delivered through the years, have had important social impact but no economical. Therefore, we propose that an important factor is that university $R \& D$ entities must develop stronger links with both, private companies and public organizations. Case shows that this phenomenon not only depends on the linking system performance, but also of the lack of the innovation culture among domestic entrepreneurs. The conclusion is that today's role of the public university in Mexico is the generation and knowledge transference for the social welfare and that it is
\end{abstract}


required create new ways to establish relationships with other economic actors in the Mexican innovation system, in order to promote the growth of the country's economy.

Keywords: Public University, Socio-economic system, Knowledge generation and Transfer, Mexico.

\section{Introduction}

The objective of this work is to present which is the role and the contributions of public universities within the Socio-Economic Innovation System (SEIS) of Mexico and if they can act in practice as agents for the economic development of the country through the knowledge they transfer to different society organizations.

In first place let's say that the SEIS is related to the way the society members generate knowledge, diffuse it among different society groups and afterwards assimilate and learn how to use it for its benefit and progress. A good indicator of the knowledge that a society possesses may be the indirect measurement of the technology dominated expressed in the used products and in their lifestyles.

The technology concept is traditionally understood as machines, devices and apparatus; when it includes human and social elements, the meaning of the concept expands and it is understood as knowledge. Galtung cited by Olsen \& Engen (2007, pp. 457) includes structures and social relations as part of the technology because these are the cognitive structures where knowledge acquires significance. In figure 1 we can see how the social relations around the technical knowledge application determine the nature of the resultant technology.

We understand that technology progress is closely related to the continuous process of knowledge generation, which in turn, undoubtedly is fundamental for the economic growth. Theoretically in an ideal country where its economic growth does not have social nor market imperfections, poverty diminishes and at the same time the life quality indexes increase in such a way that finally the people's life satisfaction levels improve. (Veenhoven, 2005). According with Nichols (2007, p. 370), the formula found by Rosenberg, for the wealth increase of occidental countries after the different economic revolutions has been the assignation of the necessary economic resources by the governments to perform free experimentation directed toward the organizational improvement and the technological development looking for the human requirements satisfaction.

\begin{tabular}{|c|c|c|}
\hline \multicolumn{1}{|c|}{ Lavers } & Structures \& relations & Knowledge \\
\hline What society knows and does & Social & Explicit Technologic \\
\hline What people knows and does & Organizational & Tacit Technologic \\
\hline Activities and processes & Human & Relational \\
\hline Physicalobjects and devices & Artefactual & Technical \\
\hline
\end{tabular}

Figure 1. Levels of technological knowledge generation

(Modified from Bijker, 1987). 


\section{Ml Macrothink}

Business and Economic Research

ISSN 2162-4860

2015, Vol. 5, No. 1

Furthermore, Yusuf (2009) considers that talent is the fundament of a creative and innovative society where the viable innovations are precursors to success in global markets and have helped to increment the total productivity in the countries with advanced industrial economies. (OCDE, 2006). But, what are the contributions, others than teaching, of the public University in the construction of the knowledge and technology layers that promote the transformation of the social relations and structures? To answer this, in figure 2 we propose that University knowledge generation and its transfer to other society agents are important steps within a linear simple route between talent and countries competitiveness.

Then, as Etzkowitz and Leydesdorff (1997) proposed, the place of Universities is fundamental in the system of institutions involved in the contemporary knowledge production system and the growth of the other societal sectors as hospitals, industries and governments laboratories is strongly linked to universities. (Godin and Gingras, 2000).

In base to the model above, in figure 3 we disclose and identify some simple elements within the talent-knowledge generation-competitiveness conversion process. The process inputs are the technology; the previous knowledge and the capital invested in the realization of multiple inter institutional projects required by the different society and economic sectors. Here we have a multiplier effect since the results of the projects beyond be delivered and be applied to the society sector that financed and required them, generates knowledge that is possible to be applied in other economic sectors of society. The interaction and the continuous functionality of the elements that conforms the SEIS contributes substantially with the technological progress and the economic growth of a country.

The fundamental input for the system is the human talent available in the society, who permits the realization of good $R \& D$ projects and the efficient and rational application of the economic resources scarce and limited. Talent is also the source of the creativity, the generation and the learning of new technological knowledge. Technological progress can follow at least two different routes: (a) the commercialization of the new technological products to drive entrepreneurial development and to increase the employment and capital growth or, (b) encourages positive social impacts when it is directly applied to strategic sectors as: health, education, environment, among many others. The non-written goal of the SEIS, is that the results obtained in the different economic sectors have a positive impact in the national competitiveness fostering at the same time the social and economic growth in order to improve the indexes of life quality and of life satisfaction of the members of the society. 


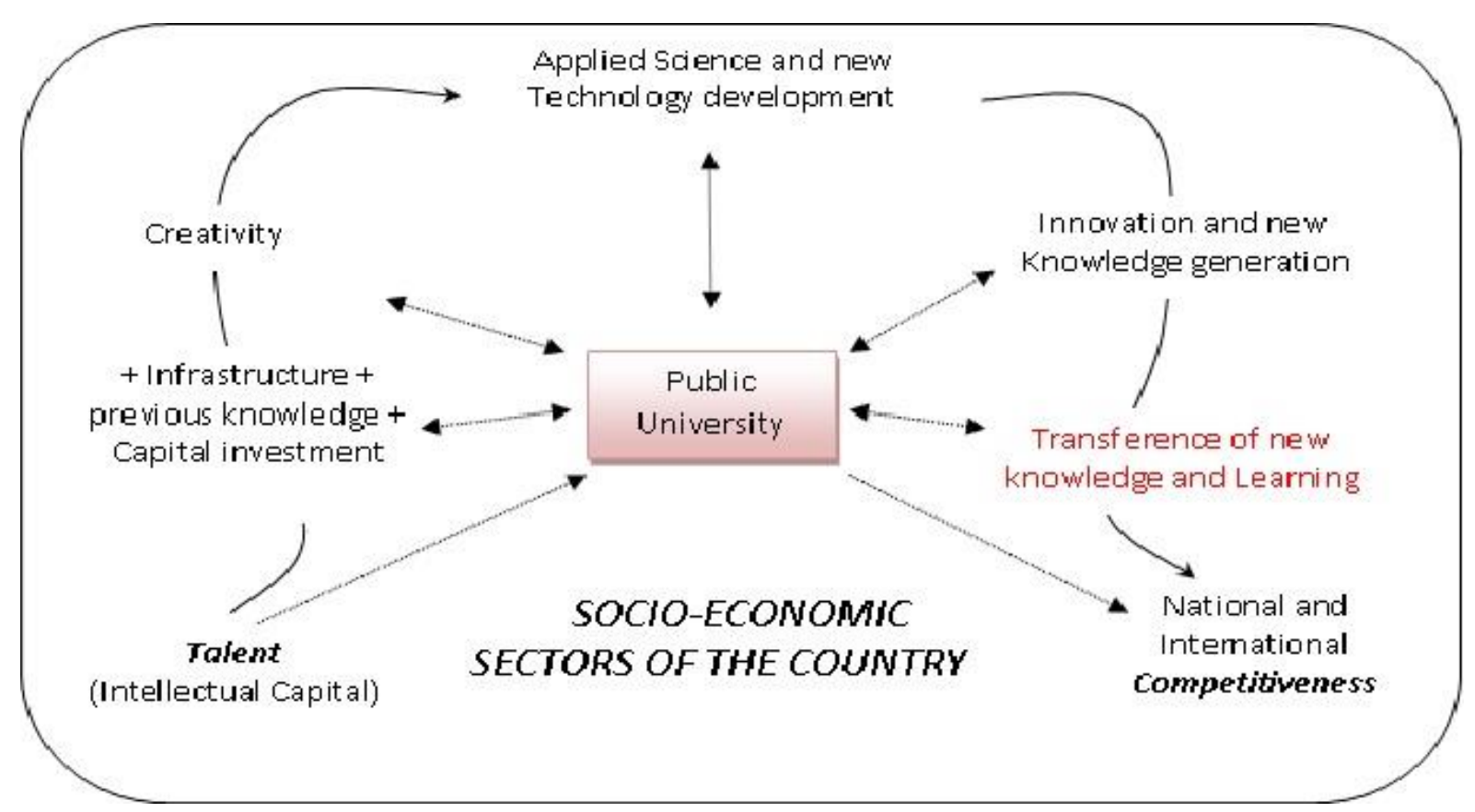

Figure 2. Public university innovation ecosystem in the route from talent toward

Competiveness of a country

In order to know what is the role of public universities in the macro processes described that result in economic and social growth; we need to discuss what has been its role and main objectives through the years.
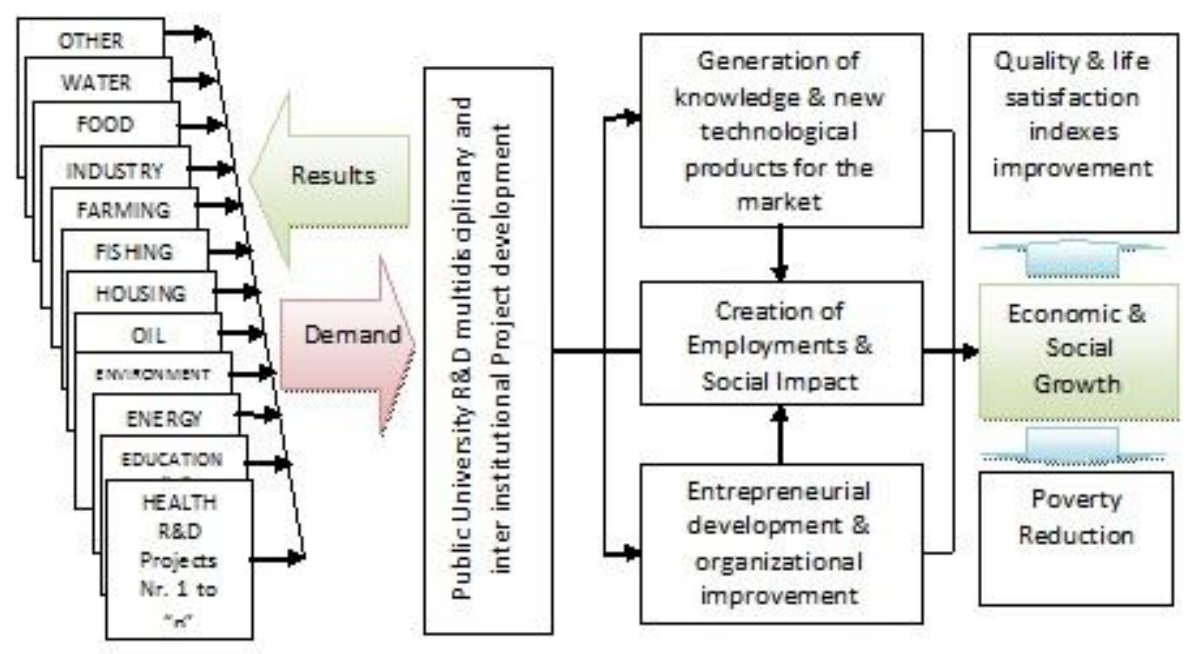

Figure 3. Knowledge generation and socio-economic effects in the

Talent-competitiveness conversion process

\section{Evolution of the role of Public Universities ${ }^{1}$}

Since its origins the first mission of the public university was the human resources formation

${ }^{1}$ In this work the term universities will include all public technology development institutions 
through democratic teaching, characterized by the equality of membership, because individuals belonging to different groups should have equal access to educational opportunities. (Anderson, 1995, pp.186).

Before World War II the federal US government provided relatively little support for research in universities. After WWII, there was an historic decision to establish a comprehensive policy on the role of the federal government to support both basic research and the research necessary for government agencies to perform their missions in the post-World War II era. Vannevar Bush, President Roosevelt's science advisor, outlined this policy in his 1945 report "Science, the endless frontier". By the middle of the 20th century, research was fully recognized in the first world as the second main mission of the University and research partnerships with industry flourished in the early years of the century. Nathan Rosenberg (2010, pp. 208) pointed out that the universities have had two major roles to play: (1) they trained scientists and engineers many of whom would eventually take up employment in corporate labs where their training might make essential contributions to innovative activities and also (2) graduate students at American universities participated in various kinds of research that would push out the frontiers of useful knowledge.

Nevertheless, it took some decades for developing and under developed countries public universities to follow these policies. For example, in the National Autonomous University of Mexico the Astronomy, the Geology and the Biology Institutes were created in 1929, the Engineering Research Institute was created in 1956, the Geophysics Institute was created in 1949, and the Physics Institute was created in 1938. (Coordinación de la Investigación Científica, CIC-UNAM, 2004). History has shown that the generation of new knowledge is one of the most important results of teaching and research.

Undoubtedly the dissemination of the knowledge generated through the realization of these two missions, has strongly improved the national culture and the quality life of all the countries. Indeed, Readings (1996) noted that historically the integrity of the modern University has been linked to the nation-state, which it has served by promoting and protecting the idea of a national culture. Nevertheless, the role that public university has been playing lately in society has changed rapidly in the last decades, and we have yet to understand what precisely these changes will mean.

The university has performed systematic research since last century and therefore has been seen as a contributor to innovation and as an institution that supports the industrial R\&D. In this sense, the results of this activity have gone to extremes because while in high developed countries as the US, Mansfield \& Jeong-Yeon, (1996) indicate that between 1975 and 1985, $10 \%$ of new products and processes in high-technology industries were based on academic research and this figure has been growing since then; in the less developed countries of the world, as in Africa and Latin America it is evident the lack of linkages between the R\&D organizations and the universities; therefore, this process require the back up of institutional mechanisms to function. (Mwamila \& Diyamet, 2009; Saad \& Zawdie, 2011; Villasana, 2011). Furthermore, in the underdeveloped and in the developing countries, Godin \& Gibras (op. cit.) propose that the universities develop only a small part, of the knowledge produced in all 
society sectors. (Gibbons et al., 1994, p. 85.)

Etzkowitz et al. (2000) indicate that at late $20^{\text {th }}$ century promoted by the second academic revolution, arrived the third university mission of economic development, they argue that this shift arises from both, the internal development of the university and external influences on academic structures associated with the emergence of knowledge innovation. Consequently the new mission of economic development of the university promoted the development of entrepreneurial activities and motivated the appearance of the entrepreneurial teacher and the entrepreneurial scientist. (Etzkowitz, 1998). As a backlash, many society actors view the new entrepreneurial paradigm of the university like a threat for the traditional integrity of the university in the sense that the increasing pecuniary interest will cause the loss of the university role as independent critic of the society. (Pelikan, 1992., Krimsky, 1991., cited by Etzkowitz et al, 2000., p. 314).

Today, it seems that the concept of nation-state is in decline, and national culture no longer needs to be either promoted or protected. Increasingly, universities of developed countries are turning into transnational corporations, and the idea of culture is being replaced by the discourse of "excellence." On the surface, this does not seem particularly pernicious. The problem is that if the new university of excellence is a corporation driven by market forces, will be more naturally interested in profit margins than in thought. (Readings, op. cit). Therefore the university will pass from being more than a knowledge producer and disseminating institution to a human capital provider and seed-bed of new firms directed toward the capitalization of knowledge.

With the emergence of the social entrepreneurship in the first decade of 21st century the university social function is having a new light. (Shaw \& Carter, 2007). The term social entrepreneurship has emerged for describing the work of community, voluntary and public organizations as well as private firms for social rather than for profit objectives. The aim of social entrepreneurship is to create social value rather than personal and shareholder wealth (Zadek \& Thake, 1997, cited by Austin et al., 2006). Today public university can consider being a social institutional entrepreneur since it can be more concerned with caring and helping than with making money. (Thompson, 2002; Mair \& Marti, 2006).

In this sense, as happens in the entire world, in the developing countries, the generation and the transference of the knowledge generated by the public universities to other society sectors play an important role for the socio-economic innovation system sustainability. Mexican universities have been generating useful knowledge for the society through their engineering schools, Centers and institutes performing their main basic objectives of human resources formation and the research and development (R\&D).

Similarly to what happened in developed countries, the internal development of the university and the external influences on academic structures associated with the emergence of 'knowledge-based' innovation has shifted the mission of the public universities expanded it from teaching and research to the third mission of economic development.

In Mexico public universities are the institutions that inexpensively form the required 
professional, MSs, $\mathrm{PhD}$ 's and specialists required by the society to handle the existing industrial technology platforms and the emergent ones to maintain in operation the scientific and technological systems in the different economic and societal subsystems allowing the country economic growth. As occurs in the entire world the knowledge generated by these institutions becomes explicit through the issuing of indexed international scientific articles, books, manuals, social and experimental sciences and investigation reports, among many other products. They also develop technology in the form of apparatus, devices, processes, manufacturing systems, software, so on.

Although, the knowledge generated by the public universities can be intellectually protected by means of patents, trademarks, copyrights, and other intellectual property figures., frequently it is protected just keeping the industrial secret, since there is a fundamental contradiction with the monopoly and the exploitation rights given by the government via the intellectual property system and the universities purpose of free knowledge diffusion to the society. The way this contradiction is overcomed, changes from country to country and even from university to university depending on their operating regulations, laws and politics.

\section{The Linking Process of the Public Universities Entities with Other Society Sectors}

As mentioned before, since the end of last century the universities in the world have been playing an enhanced role in technological innovation and have been recognized as key players in national and regional innovation systems, producing knowledge and actively participating in industrial innovation processes. (Etzkowitz, et al., 2000; Saad \& Zawdie, 2011). This situation has prompted many governments in both developed and developing countries to introduce a range of policies that would encourage the development of strong linkages among universities, industry and other institutional and organizational actors in the wider social and economic environment.

The importance of the interface processes between the different university entities with other institutional spheres as industry and government was recognized by Etzkowitz et al. (2000., pp 316) pointing out that actual university requires enhanced capability for intelligence, monitoring and negotiation. In their study about the Innovativeness of firms and interaction with the science system in Europe, Kaufmann and Tödtling (2001), demonstrated that partners from science are more important than the firm's customers for the introduction of new products to market.

Every project that the universities entities develop depends on the priorities, objectives, economic resources, intentions and even desires of the counterparts, for that reason the linking and negotiation processes are very important for both organizations. This seems to be axiomatic, but must be recognized in order to understand the rest of the processes required for the transfer of knowledge. Figure 4 shows a model of the linking processes among an R\&D Center of a Mexican public university and other society sectors.

In the model we can see that there are at least two levels of links among the R\&D Center and other social sectors. In the middle of the figure we have the R\&D Center, the next circle is formed by other public institutions like medical Centers, general hospitals, medical research institutes, research institutes and federal secretaries for water, oil, electricity, public education, 
social security, transportations, police and safety departments, among many others. Most of them are public institutions devoted to attend specific societal problems within the social sectors where they are directly linked.

Therefore, when the results of the $R \& D$ projects obtained by the linking activities are technological products as apparatus, devices, software systems, new operational and logistics systems or new service products, among many others, the R\&D Center officials think about the best intellectual property strategy to protect the developed knowledge and to make them available to be transferred to the user. All the titles and certificates available in the intellectual property system are used, in a balanced cost-benefit relation. This situation reinforces the fact that an important part of the knowledge needs to be kept via industrial secret.

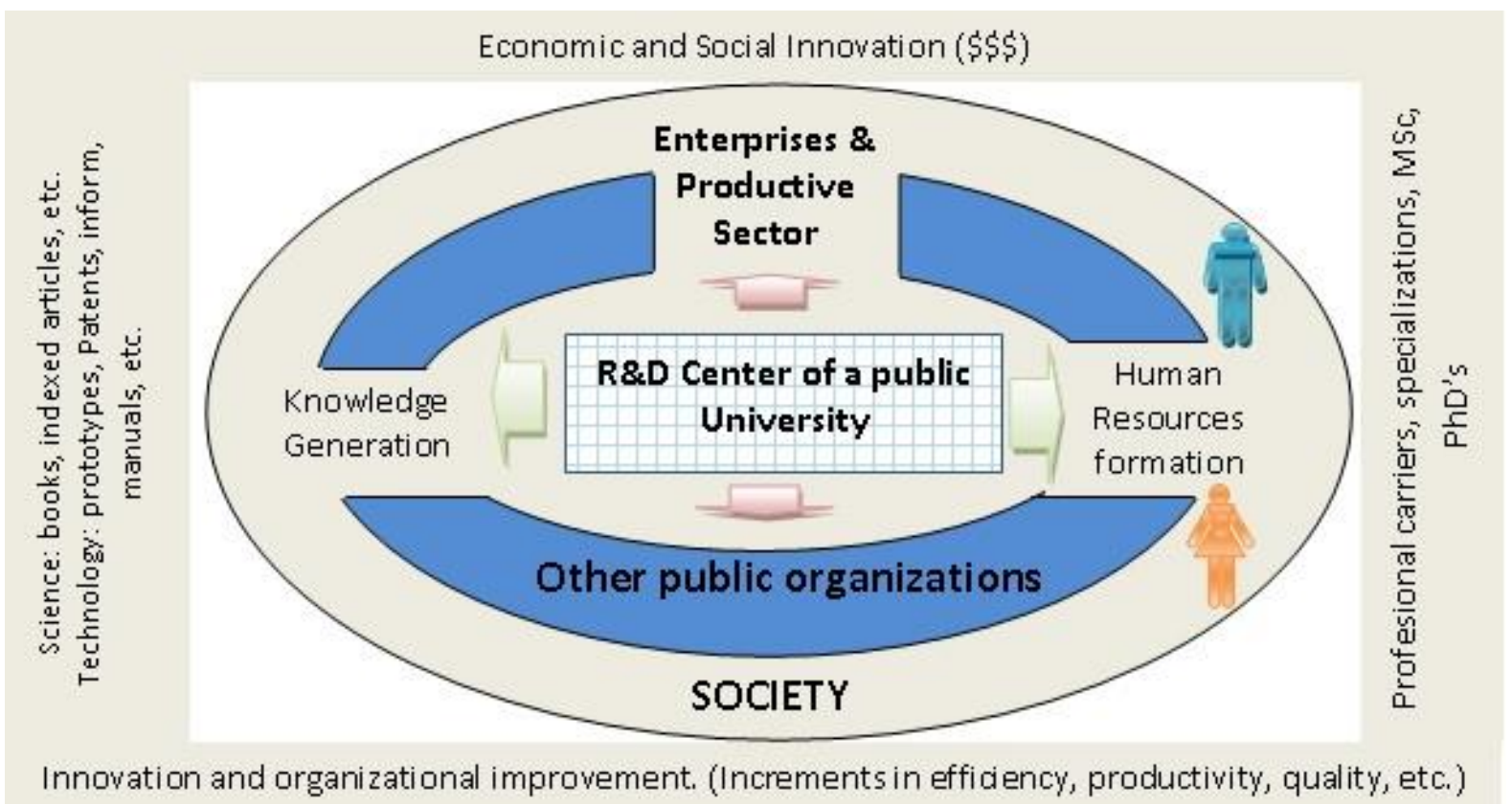

Figure 4. Basic model of the linking process among society sectors and public university

The organization gives moral acknowledgment to the academic inventors in the patents and copyrights and other intellectual property legal instruments. The IP instruments are legal and commercial instruments used for licensing and selling the technology to obtain economic funds that will be used in the realization of new investigations and to benefit the inventors.

Private organizations are located in the external circuit of figure 4. They are usually manufacturers and industrial firms, as well as specialized services providers organizations, among others. As a result of the differences in their main objectives, the linking of the R\&D public institutions and the private organizations turns very difficult.

To overcome their objectives difference and obtain successful links and projects, the R\&D institutions within the public universities must have the awareness of their social responsibility because they have obtained from the society the infrastructure and economic resources required to hire the specialized intellectual capital making possible its functionality and growth. 
Along the years Mexican public universities have accomplished its social responsibility through the human resources formation, the investigation and the culture diffusion; nevertheless, today's dynamics of technological change has been intensively fostered by the technology of information and communications and continues strongly transforming to the society.

Additionally, the population in developing countries has grown substantially but in contradiction neither the proprietary technology nor industry have been enough developed to fully address the alimentary and primary needs of our countries. To make matters worse, saturation signs within the education system have appeared, that is, a lot of graduates of schools and universities do not find employment and pass to the informal economy when they get their grade. At the same time population requires more quantities of energy, water, health and education services, security, and it seems to be a vicious circle.

In this context and within the intense global economic competition, public universities entities that develop R\&D must find the way to be sustainable and return to the society part of the resources invested in them by the state. Furthermore, they have to make efforts to back up other economic sectors as the private enterprises through the transference of the knowledge they generate.

\section{Knowledge Transference from R\&D Entities of Public University to Other Organizations}

Lee (1996), pointed out the existence of a debate on the knowledge transfer of the US universities, characterized because there is the perception in some people that the declining of federal support to R\&D, will threaten the vitality of their basic research, while other people think that the impact of close university-industry cooperation could interfere with the actual academic freedom to pursue long term disinterested fundamental research. Marques et al., (2006) precise that in the present time, more than in the past, the performance of a system of innovation relies on the intensity and efficiency of the interactions between the chief agents involved in the generation and dissemination of knowledge.

The Mexican productive sector is aware of this situation, but is notorious that the public universities in the country have more links with other public organizations than with private organizations. Probably the reason is that both receive their financing from federal government funds and have the common objective of improving the population welfare. In practice what has been happening is that the first level of knowledge transference goes from the university to other public organizations within the societal system that have responsibilities in maintaining and improving the population requirements in aspects as diverse as health, education, environment, energy, security and food supply, among many others.

In figure 5 we have a representation of the different processes that occur from the technology development to the knowledge transference from any University entity to other public institutions or private firms. The assimilation, implementation and integration of the technology in the existing productive system could improve the existing products and/or services or causes the introduction of new products to market. Let's suppose that the whole 
process is detonated in the upper left side of figure 5, by the request of new technology in the form of software or hardware or combinations of both by an external public organization to the public University. The parts begin working once the institutions agree on the specifications, a legal agreement is signed and the economic funds are allocated.

In the first stage the universities perform investments of their resources in making basic and applied research to obtain experimental prototypes. Later, in the technological development stage, they perform the proof of concept and of functionality and obtain laboratory prototypes of the new, adapted, improved, or optimized production methods or the systems required. At that point the first knowledge transference $\left(\mathrm{KT}_{1}\right)$ is carried on. Staff of public organization that requires technology receive it in the form of prototypes, apparatus, devices, manuals, documentation, software, patents, copyrights and so on,. Then the receiving organization starts the assimilation and adaptation of the technology stage.

If the deliverable was a laboratory prototype, the next step is the engineering development, normally performed by the requesting organization; it consists of the integration of the new technology with the process and systems that this organization previously owned. A second knowledge transference $\left(K T_{2}\right)$ between different areas of the requesting organization could be required; i.e. the department of engineering receives the technology from the university, then they could perform internal researches for the optimization of their services, processes, products, systems, and procedures, so on.

Afterwards, they pass the adapted knowledge to the production department who will implement it and can be the final internal user. To implement the new technology sometimes final operational adjustments are required.

The final internal user frequently faces the users of the general society; for instance, the patients in a hospital, the teachers in a school, the government water agent, etc. Once the new technology is assimilated and is implemented in the requesting organization, the improved product or service is offered to the users of the services of the requesting public organization. This is the end of the process that will have indirect economic and social impacts. The continuous identification of opportunity areas and improvements must be achieved. The expectation is that the implanted new technology will produce better and low cost services to the final users.

A different way of knowledge transference from Mexican public universities is done to private firms, who through the identification of their core competences pretend to leverage the corporation resources (Prahalad, 1993) and improve their local and global competitiveness, (Prahalad and Hamel, 2009), in the search for innovation. In that sense, we understand innovation as Godin \& Lane, (2012, pp. 13) in a large sense: a good, a service, a method, a protocol, a policy or law, briefly stated: anything that is useful to society.

Is important to note that Prahalad emphasized, (op. cit., pp. 45) that in an enterprise the core competences are obtained when the firm is capable to harmonize multiple technologies, including of course, those received from the universities.

Braga et al., (2009) note that there is no firm capable to develop all the technology they need to 
foster their competitiveness, therefore frequently in many countries of the world, industrial firms establish links with the universities searching for R\&D to support and complement their innovation efforts. Mansfield \& Lee (1996) have found that in the USA the industry financed about $\$ 1.5$ billion of research and development performed at colleges and universities and probably has doubled since then. This is very far from what happens in Mexico, where the industry is practically divorced of universities and there are no records of the economic resources that they provide to universities for R\&D purposes. In general it is known that public Universities are less linked to enterprises than to other public organizations.

The first part of the whole knowledge transfer process previously described, is fairly the same, for both public and private organizations; but, depending with the scope of the contract, sometimes the university gets a leading role in the engineering development stage that occurs within the innovation process. To illustrate how the linking system and technology transfer theoretical issues are occurring in reality, in next section we present the results of an $R \& D$ Center of a known public University.

\section{Case of Centro De Ciencias Aplicadas Y Desarrollo TecnolÓGico (CCADET)}

The CCADET is a Center that is part of the scientific research subsystem of the Universidad Nacional Autónoma de México (UNAM) which is a well-known national public university in Mexico. It was created in 1971 and their main objectives are: the human resources formation, perform research and development, and the diffusion of its results to the society.

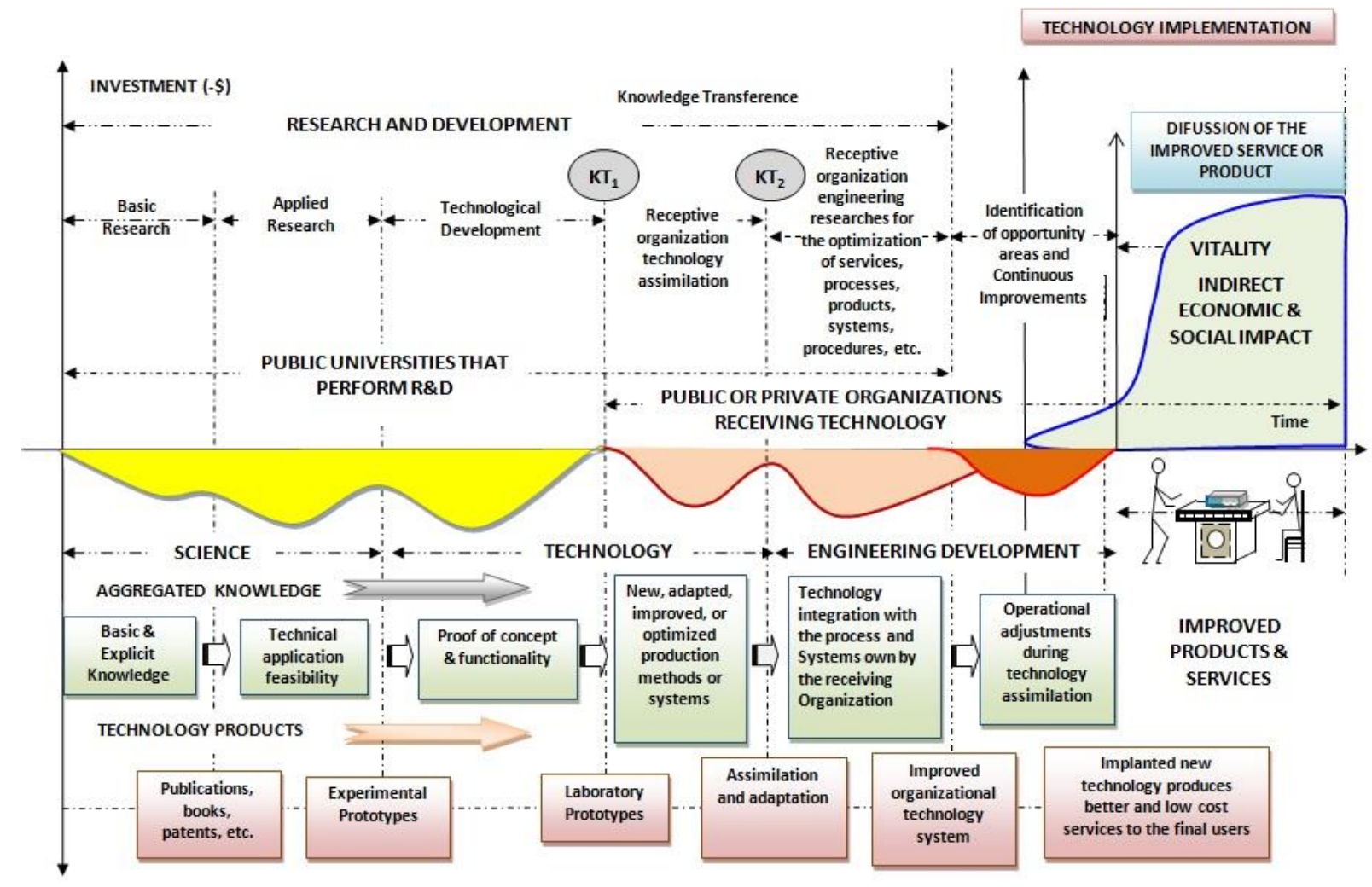

Figure 5. Linear knowledge transference process from public university to other organizations. Vega-González (2012). 


\section{Macrothink Institute ${ }^{\mathrm{TM}}$}

In 1999 the CCADET's Office for Linking and Technological Management was created as the responsible entity of transfer, spread and divulge the scientific and technologic knowledge generated at the Center. It also promotes and administrates the Center's intellectual property titles.

CCADET has about 104 academics, of which 34 are $\mathrm{PhD}$ researchers, 67 are academic technicians with Masters in sciences or engineering (Ms, Me), and some are professionals in engineering and design. There are about 200 people for support and administrative purposes. The organization structure has four academic departments which are: Instrumentation \& Measurement, Applied Optics, Techno sciences and Education in Science and Technology. Each department has about six or seven different academic groups.

The personnel of the CCADET develop projects of basic and applied research and technology development. Nearly always the project team is formed by the titular researcher who is the head of the project and some assistant researchers and students of doctorate and master. Generally speaking, the financing of the basic research projects comes from the CCADET's internal budget and from the Consejo Nacional de Ciencia y Tecnología (CONACYT) which is the federal government agency uncharged of the promotion and development of science and technology in the country.

There are different financing ways for the projects of applied research and technology development, it depends in the economic capacity of the external organization that request the R\&D support, but they also can receive economic support from CONACYT who also has programs to support the financing of technology development projects in private firms.

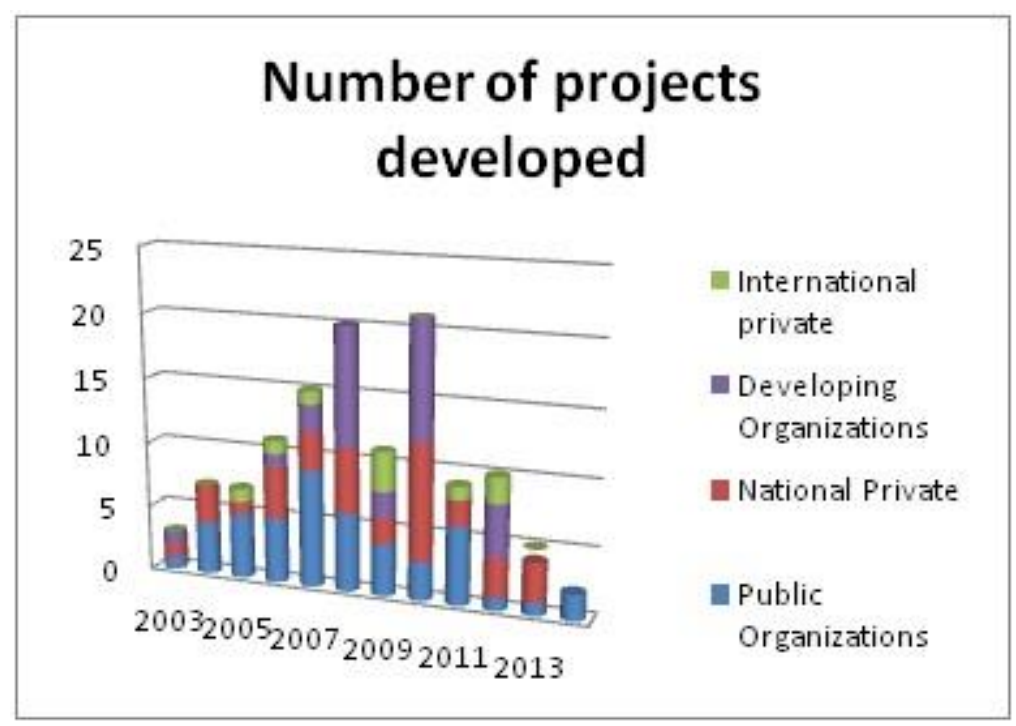

Figure 6. Externally financed projects developed by the CCADET

Figure 6 shows the number of externally financed projects performed by the academic groups of the Center between the years 2003 to 2013 indicating the type of sponsoring organization. During those years there were developed an average of 12 projects by year with an average external financing of less than $\$ 70,000.00$ USD by project. 


\section{Ml Macrothink}

Business and Economic Research

ISSN 2162-4860

2015, Vol. 5, No. 1

The projects were mainly developed for public external organizations, almost all governmental. The Center also received financing from CONACYT which is the Federal Government developing institution and from the Instituto de Ciencia y Tecnología del Distrito Federal (ICYTDF) developing institution that depended on the Mexico City local Government. They both delivered financing to support governmental institutions as the following Federal Secretaries: Health, Economy, the Public Education, the Environment, and the Social Development, among many others.

The type of technology products delivered in the projects contracted by the Center with external organizations in the years studied is shown in figure 7 . The contracts percentage to realize research and/or for consulting services was $43 \%$, similarly for the development of didactic materials and prototypes for science teaching the percentage was $18 \%$. The third strength corresponded to the Information Technologies department who delivered software systems for specific purposes with $17 \%$ of the contracts. The Center received $14 \%$ of their contracts to perform specialized services and manufacturing. Finally there were only $8 \%$ collaboration agreements for the development of software embedded in integrated prototypes and apparatus.

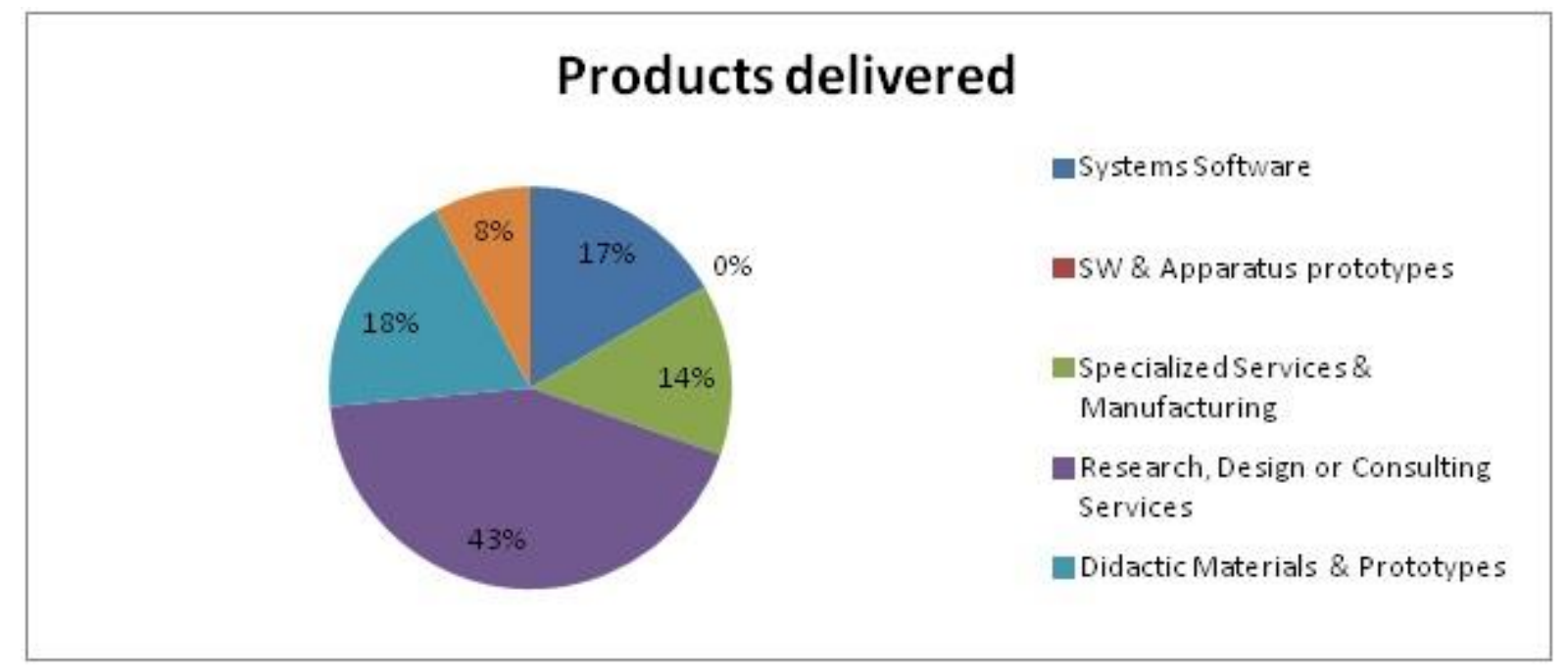

Figure 7. Percentage of technology products delivered to the Center clients.

\section{Discussion}

As we have seen, along the last decade, the Center was been mainly linked to external public organizations, via collaboration agreements, receiving direct financing from them or through agreements signed with external governmental developing Institutions who alternatively provide the financing for the projects requested. It is evident that the national private firms provide a major number of requests but with lower financing amount than the international private firms. This is a sign that they have no enough trust and are adverse to risk. Therefore, they just require from the Center specialized services, consultancy measurements, and so on.

During the time period mentioned, the Centre signed $88.45 \%$ of all their externally financed contracts with other public organizations, $4.6 \%$ with private international and $6.95 \%$ with 
national private organizations. The main products delivered to the customers have been consultancy informs specific application software, didactic materials and specialized services. The institution developed an average of three to four functional laboratory prototypes devices but since approximately $90 \%$ of them are delivered to other public organizations. The purpose of those devices and lab technology developed will be the improvement of the requesting organization internal processes; indeed they will never get the level of a market innovation.

This phenomenon is quite similar to what happen with the other 30 institutes and Centers and even at the engineering schools of the UNAM. Hence, data suggest that the National Autonomous University of Mexico is not having an important participation at the commercial innovation efforts in the SEIS of Mexico. The situation is also similar to what happen in public universities of other states of the Mexican Republic, i.e the Universidad Autónoma de Guadalajara, the Benemerita Universidad Autónoma de Puebla, the Universidad Autónoma de Yucatán, among others. It is possible that the Universidad Autónoma de Nuevo León could have a higher level of links with the private industry in the Nuevo Leon State, especially at the city of Monterrey. Nevertheless, according with the empirical investigation of Villasana (2011) about how academic researchers of the largest private and public universities in that northern Mexican state, develop interactions with biotechnology industry, the main motivation of the researchers at both universities is the social impact that their research may have.

Under the point of view of the economic theory, in order to foster the nation's economic growth the university must transfer the knowledge and the technology they generate to manufacturing and commercialization firms interacting with other public industrial firms, generating economic resources by selling their products and pushing the growth of the economy.

According with Rosenberg (op. cit., pp.208), America's commercial success in high tech markets over the past 50 years have owed a great deal to the internal competences in private industry given by the industrial scientists who have played a critical role in the transfer of potentially useful knowledge generated by university research, not only because of their scientific sophistication, but also because they have had a deep awareness of their firm's commercial priorities and technological capabilities. In Mexico and probably in the other Latino America developing countries this situation cannot be replicated since only a portion of the big companies, who constituted about $1.5 \%$ off all the county enterprises, have corporate labs with the capability to get the university knowledge transferred and to transform it into new products and services. The $99 \%$ of the companies are micro and small with low innovation opportunities. (Diario Oficial, 2008).

\section{Conclusions}

According with the Foro Consultivo y Tecnológico (2006), it is necessary the articulation of the knowledge value chains beginning by the superior education, the science and technology system and the innovation for the employments, welfare, governability and social security creation. Lederman (2006) affirms that the National Innovation System of Mexico has been inefficient in the action of transforming $R \& D$ investment into successful commercial ideas. He also states that the deficient performance of Mexico in innovation is the result of the low $\mathrm{R} \& \mathrm{D}$ private and governmental investment and the lack of cooperation between the private 
firms and the university researchers.

The case presented is an evidence of the large distance existing between the public university and the private industry in Mexico. Nevertheless the public university in Mexico is doing a good work since the main mission of the UNAM establishes that one of the university's goals is to contribute in the solution of the national problems. Therefore, delivering and transferring technology to public not lucrative organizations means to help those societal sectors indirectly. For example, the technology is delivered to the Federal Ministries of Health, Energy and Education among many others, and its use produces social welfare without passing through a commercialization process.

The funding of the Mexican public universities is completely centralized, therefore the way in which they operate and its historical performance show that these institutions are fundamentally society servants with no clear commercial orientation; besides of that, along its history, those institutions have always been knowledge producers that had promoted the social welfare with no profit objectives.

In the presented case, the largest number of the projects performed by the R\&D Centre was developed to governmental institutions. Extrapolating these results, to other R\&D institutions within the university, we suggest that it can be considered more as a social entrepreneur than a profitable economic entity. Accordingly, we conclude that besides teaching and performing $\mathrm{R} \& \mathrm{D}$, the actual role of the public university in Mexico is the generation and knowledge transference for the social welfare. In Mexico, as well as in other developing countries, the public university is doing a good work but, in order to impulse the nation's economic growth, it is necessary to find the ways to establish more and stronger links with other public economic actors.

\section{References}

Anderson, E. S., (1995). Social Philosophy and Policy Foundation. USA.

Austin, J., Stevenson, H., Wei-Skillern, J., (2006). Social and commercial Entrepreneurship: Same, Different, or Both? Entrepreneurship Theory and Practice, pp. 1-21. http://dx.doi.org/10.1111/j.1540-6520.2006.00107.x

Barr, SH., Baker T, Markham, Steven K., (2009). Bridging the Valley of Death: Lessons Learned From 14 Years of Commercialization of Technology Education. Academy of Management Learning \& Education. Vol.8, Issue 3, pp.370-388. http://dx.doi.org/10.5465/AMLE.2009.44287937

Bijker, W. E., (1987). The social construction of facts and artefacts. In: Bijker WE, Hughes TP, Pinch T, editors. The social construction of large technological systems. Cambridge, MA: MIT Press.

Braga, E., Pio, M., Antunes, A., (2009). O Processo de Transferência de Tecnologia na industria Têxtil. Journal of Technology Management \& Innovation. 4(1), 125-133. http://dx.doi.org/10.4067/S0718-27242009000100011 
Coordinación de la Investigación Científica, CIC-UNAM, (2004). Ciencia, Estrategias de Desarrollo del Subsistema de la Investigación Científica. Universidad Nacional Autónoma de México., pp. 302.

Diario Oficial de la Federación, (2008). Acuerdo por el que se establecen las Reglas de Operación para el otorgamiento de Apoyos del Fondo de Apoyo para la Micro, Pequeña y Mediana Empresa (FONDO PyME). Decimoquinta Sección. Secretaría de Economía.

Etzkowitz, H., Leydesdorff, L., (1997). Universities and the Global Knowledge Economy: A Triple Helix of University-Industry-Government Relations. Pinter, London.

Etzkowitz, H., (1998). The norms of entrepreneurial science: cognitive effects of the new university-industry linkages. Research Policy, 27, 823-833. http://dx.doi.org/10.1016/S0048-7333(98)00093-6

Etzkowitz, H. A., Webster; Gebhardt, G., Terra, B. R. C., (2000). The future of the university and the university of the future: evolution of ivory tower to entrepreneurial paradigm. Research Policy, 29(2), 313-330. http://dx.doi.org/10.1016/S0048-7333(99)00069-4

Foro Consultivo Científico y Tecnológico, (2006). Conocimiento e Innovación en México, hacia una política de Estado. Elementos para el Plan Nacional de Desarrollo y el Programa de Gobierno 2006-2012. Disponible en: http://www.foroconsultivo.org.mx/libros_editados/conocimiento_innovacion.pdf ; Consultado 25 de julio 2009.

Godin, B., Gingras, Y., (2000). The place of universities in the system of knowledge production. Research Policy. 29, 273-278. http://dx.doi.org/10.1016/S0048-7333(99)00065-7

Lederman, D., Innovación en México, World Bank, Oficina del Economista en Jefe para América Latina y el Caribe. Disponible en:

http://wbln0018.worldbank.org/lac/lacinfoclient.nsf/d29684951174975c85256735007fef12/f7 cde0329889f57d85256dc50056268a/\$FILE/Mexico_Innovation\%20Brief_spa.pdf;

(Consultado en 2006)

Godin, B., Lane, J. P., (2012). A century of talks on research: what happened to development and production? Int. J. Transitions and Innovation Systems, 2(1), 5-13.

Kaufmann, A., Tödtling, F., (2001). Science-industry interaction in the process of innovation: the importance of boundary-crossing between systems. Research Policy, 30, 791-804. http://dx.doi.org/10.1016/S0048-7333(00)00118-9

Lee, Y. S., (1996). Technology transfer and the research university: a search for the boundaries of university-industry collaboration. Research Policy, 25, 843-863. http://dx.doi.org/10.1016/0048-7333(95)00857-8

Mair, J., Marti, I., (2006). Social entrepreneurship research: A source of explanation, prediction and delight. Journal of World Business. 41, 36-44. http://dx.doi.org/10.1016/j.jwb.2005.09.002 Mansfield, E., Jeong-Yeon, L., (1996). The modern university: contributor to industrial 
innovation and recipient of industrial R\&D support. Research Policy. 25, 1047-1058. http://dx.doi.org/10.1016/S0048-7333(96)00893-1

Marques, J. P. C., Caraça, J. M. G., Diz, H., (2006). How can university-industry-government interactions change the innovation scenario in Portugal? - the case of the University of Coimbra. Technovation. 26, 534-542. http://dx.doi.org/10.1016/j.technovation.2005.04.005

Mwamila, B. L. M., Diyamet, B. D., (2009). Universities and socio-economic development in Tanzania: public perceptions and realities on the ground. Science and Public Policy. 36(2), 85-90. http://dx.doi.org/10.3152/030234209X406827

Nichols; R. W., (2007), Perspectives on science and technology in development: does the urgent drive out the important? Technology in Society. 29, 369-377.

Olsen, O. E., Engen, O. A., (2007). Technological change as a trade-off between social construction and technological paradigms. Technology in Society. 29, 456-468. http://dx.doi.org/10.1016/j.techsoc.2007.08.006

Organization for the Economic Cooperation \& Development OECD, (2006), Competitive cities in the global economy. Paris.

Prahalad, C. K., (1993). The role of core competencies in the corporation. Research Technology Management, 36(6), 40-47.

Prahalad, C. K., \& Gary Hamel (2009). The Core Competence of the Corporation, Harvard Business School Press, USA.

Readings, W., (1996). The University in Ruins. Harvard University Press, Cambridge.

Rosenberg, N., (2010). Studies on Science and the Innovation Process. World Scientific Publishing Co., pp. 412.

Saad, M., Zawdie, G., (2011). Introduction to special issue: The emerging role of universities in socio-economic development through knowledge networking. Science and Public Policy, 38(1), pages 3-6 http://dx.doi.org/10.3152/030234211X12960315267453

Shaw, E., Carter, S., (2007). Social Entrepreneurship: Theoretical antecedents and empirical analysis of entrepreneurial processes and outcomes. J of Small Business and Enterprise Development. 14(3), 418-434. http://dx.doi.org/10.1108/14626000710773529

Thompson, J. L., (2002). The world of the social entrepreneur. The International Journal of Public Sector Management. 15(5), 412-431. http://dx.doi.org/10.1108/09513550210435746

Veenhoven, R., (2005). Average happiness in 95 nations 1995-2005, World Database of happiness.

Vega-González, L. R., (2012). La investigación aplicada y la investigación tecnológica precursoras de la innovación social. XVI Congreso Internacional de Investigación en Ciencias Administrativas de la Academia de Ciencias Administrativas (ACACIA). Instituto Tecnológico de Estudios Superiores de Monterrey, campus Atizapan de Zaragoza, Estado de 
México.(Mayo 22 al 25).

Villasana, M., (2011). Fostering university-industry interactions under a triple helix model: the case of Nuevo Leon, Mexico. Science and Public Policy. 38(1), 43-53. http://dx.doi.org/10.3152/030234211X12924093659996

Yusuf, S., (2009). From creativity to innovation. Technology in Society. 31, 1-8. http://dx.doi.org/10.1016/j.techsoc.2008.10.007

Zadek, S., Thake, S., (1997). Send in the social entrepreneurs. New Statesman, 26(31).

\section{Copyright Disclaimer}

Copyright for this article is retained by the author(s), with first publication rights granted to the journal.

This is an open-access article distributed under the terms and conditions of the Creative Commons Attribution license (http://creativecommons.org/licenses/by/3.0/). 